\title{
Diverse modulation of spa transcription by cell wall active antibiotics in Staphylococcus aureus
}

\author{
Lene N Nielsen, Michael Roggenbuck, Jakob Haaber, Dan Ifrah and Hanne Ingmer ${ }^{*}$
}

\begin{abstract}
Background: The aim of this study was to investigate the effect of various classes of clinically relevant antibiotics at sub-lethal concentrations on virulence gene expression and biofilm formation in Staphylococcus aureus.

Findings: LaCZ promoter fusions of genes related to staphylococcal virulence were used to monitor the effects of antibiotics on gene expression in a disc diffusion assay. The selected genes were hla and spa encoding a-hemolysin and Protein A, respectively and RNAlll, the effector molecule of the agr quorum sensing system. The results were confirmed by quantitative real-time PCR. Additionally, we monitored the effect of subinhibitory concentrations of antibiotics on the ability of $S$. aureus to form biofilm in a microtiter plate assay. The results show that sub-lethal antibiotic concentrations diversely modulate expression of RNAlll, hla and spa. Consistently, expression of all three genes were repressed by aminoglycosides and induced by fluoroquinolones and penicillins. In contrast, the B-lactam sub-group cephalosporins enhanced expression of RNAlll and hla but diversely affected expression of spa. The compounds cefalotin, cefamandole, cefoxitin, ceftazidime and cefixine were found to up-regulate spa, while down-regulation was observed for cefuroxime, cefotaxime and cefepime. Interestingly, biofilm assays demonstrated that the spa-inducing cefalotin resulted in less biofilm formation compared to the spa-repressing cefotaxime.

Conclusions: We find that independently of the cephalosporin generation, cephalosporins oppositely regulate spa expression and biofilm formation. Repression of spa expression correlates with the presence of a distinct methyloxime group while induction correlates with an acidic substituted oxime group. As cephalosporines target the cell wall penicillin binding proteins we speculate that subtle differences in this interaction fine-tunes spa expression independently of agr.
\end{abstract}

Keywords: Staphylococcus aureus, Subinhibitory concentrations, Antibiotics, Virulence, Protein A (spa), Biofilm formation

\section{Findings}

\section{Background}

Small molecules, such as antibiotics, are ubiquitous in the environment whether they originate directly from producing microorganisms or are the waste products of human activities [1,2]. While the antimicrobial activity of antibiotics target basic cellular functions like DNA, protein or cell wall synthesis they also affect other processes such as virulence gene expression $[3,4]$. $\beta$ lactam-containing penicillins and cephalosporins target transpeptidase and transglycosylase domains of the bacteria. They act as pseudosubstrates and acylate the active sites of the transpeptidases (also termed penicillin-

\footnotetext{
*Correspondence: hi@life.ku.dk

Department of Veterinary Disease Biology, University of Copenhagen, Copenhagen, Denmark
}

binding proteins or PBPs) and have been widely used for treating infections including S. aureus [5].

$S$. aureus is a serious human pathogen that causes many different types of illnesses ranging from enterotoxin mediated food intoxications to more severe infections such as endocarditis, pneumonia, osteomyelitis and toxic shock [6]. The pathogen is also one of the leading causes of biofilm-associated infections that typically are chronic and frequently occur in hospitals [7]. One of the key virulence factors often studied is $\alpha$-hemolysin encoded by hla. $\alpha$-hemolysin is a pore-forming toxin that targets red and white blood cells among other cell types $[8,9]$. While toxins and degradation enzymes are produced in stationary phase, the surface located virulence factors, including the IgG binding Protein A encoded by $s p a$, are expressed in exponential phase. 
From mouse models of S. aureus infections, Protein A is known to be involved in development of pneumonia $[10,11]$. The protein has been proposed to act together with the Panton-Valentine leukocidin (PVL) to cause the severe inflammation and tissue damage seen in necrotizing pneumonia [12]. The agr quorum sensing system is the main regulator of virulence in $S$. aureus and controls the expression of at least 70 genes [13-15]. The effector molecule RNAIII inversely regulates hla (up) and spa (down) in response to increasing cell density [16].

The multitude of virulence factors contributing to the pathogenesis of $S$. aureus have spurred interest in how sub-lethal concentrations of antibiotics affect their expression and possibly modulate the outcome of infection. Exposure to macrolides, aminoglycosides and clindamycin reduces hla expression $[17,18]$ whereas $\beta$-lactams and fluoquinolones increase transcription of hla [4]. The $\beta$-lactams have been used widely to treat $S$. aureus infections and here penicillins, cephalosporins and the carbapenem imipenem all increased hla expression with the monobactam aztreonam being the only exception [4]. For the cephalosporines this stimulation is likely to involve the SaeRS two-component system as the haemolytic activity induced by cefoxitin was abolished in the absence of saeRS [19]. However, a microarray gene expression analysis revealed that additional factors might be involved in the activation of hla expression by the cephalosporin cefoxitin [19]. spa transcription was examined in response to cell wall active antibiotics, including penicillins, cephalosoprins, carbanems and glycopeptides [20]. Induction levels varied between closely related antibiotics and the authors proposed that a chlorine substitution or cephalosporin generation could be responsible for the opposite effect of various penicillins on spa expression [20].

Although only addressed in a few cases, it appears that several unrelated types of antibiotics commonly either enhance or reduce expression of all the tested virulence genes no matter whether they encode cell surface or the secreted virulence factors. As these groups of virulence factors commonly are oppositely controlled by agr this observation indicates that the altered expression elicited by antibiotics is independent of agr. To address this issue more systematically we examined the expression of RNAIII, hla and spa for several classes of antibiotics using an agar-based reporter fusion assay recording the transcriptional activity of the corresponding promoter fusions. Also we have studied in details, the diverse modulation of spa transcription by various cephalosporins.

\section{Results and discussion}

Antibiotics modulate RNAIII, spa and hla differently

We have used $S$. aureus strains carrying promoter $1 a c Z$ fusions in RNAIII, hla and spa to study the transcriptional effects of antibiotics on virulence gene expression. We investigated the impact of a wide range of antibiotics including cell wall active antibiotics, that are the drug of choice when treating staphylococcal infections [20]. A disc diffusion assay was used for a broad screen of modulation of RNAIII, spa and hla transcription by various types of antibiotics (see Figure 1 for the cephalosporin representatives). A qualitative measure of gene expression was obtained by evaluation of the color intensity of the ring surrounding the inhibition zone (Figure 1). Results are listed in Table 1. The screen shows that the tested aminoglycosides reduced transcription of all reporter fusions, while fluorquinolones stimulated their transcription. On the other hand, while all $\beta$-lactams stimulated transcription of RNAIII and hla some enhanced and others reduced transcription of $s p a$. The differentiated spa regulation was restricted to the cephalosporin group within the $\beta$-lactam family.

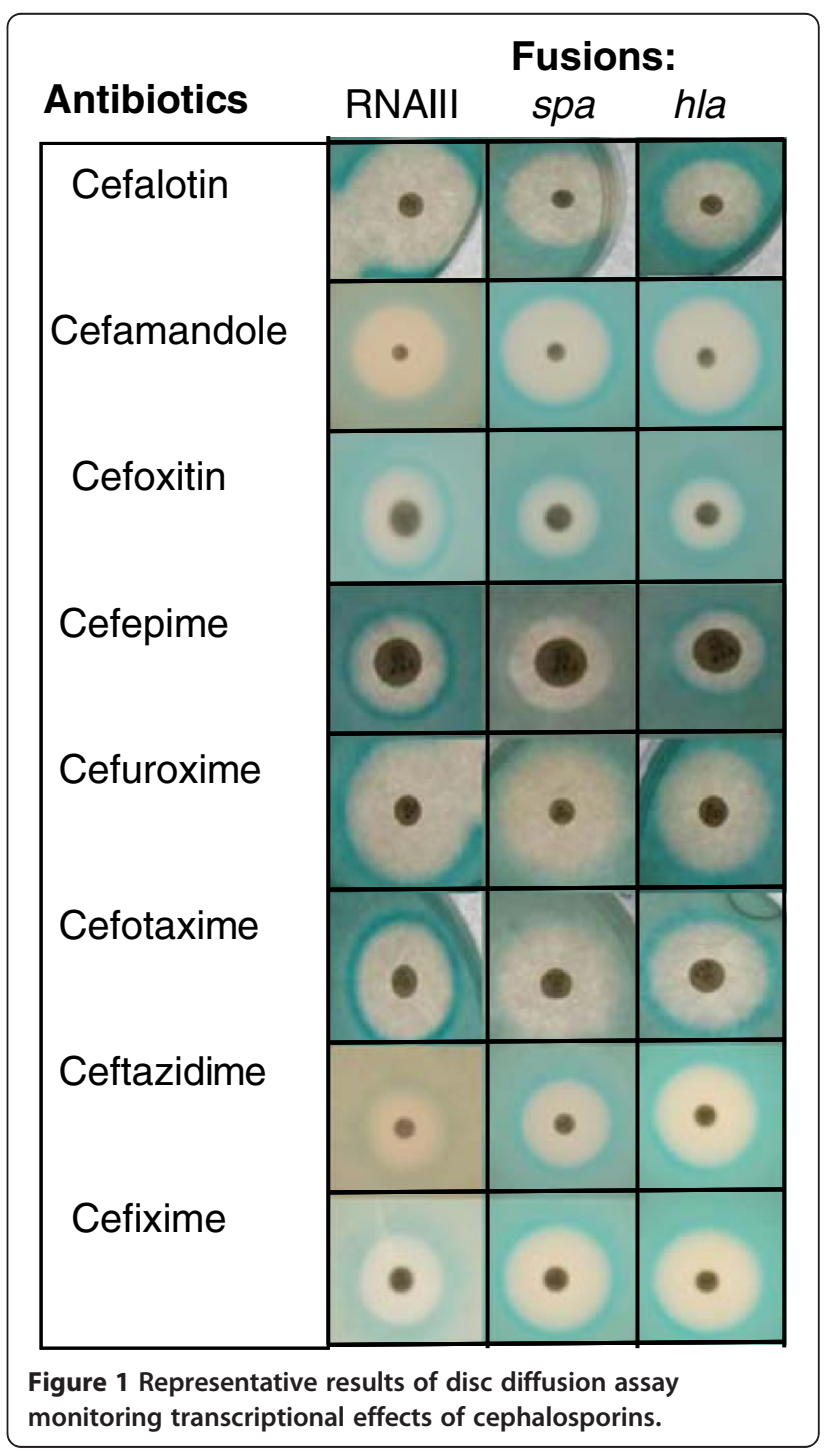


Table 1 Disc diffusion assay

\begin{tabular}{|c|c|c|c|c|c|}
\hline Class & Group & Antibiotics & rnalll & spa & hla \\
\hline \multirow[t]{6}{*}{ Aminoglycosides } & & amikacin & - & - & - \\
\hline & & kanamycin & - & - & - \\
\hline & & gentamycin & - & - & - \\
\hline & & spectinomycin & - & - & - \\
\hline & & streptomycin & - & - & - \\
\hline & & tobramycin & - & - & - \\
\hline \multirow[t]{2}{*}{ Fluoroquinolones } & & ciprofloxacin, & + & + & + \\
\hline & & enfrofloxacin & + & + & + \\
\hline \multirow[t]{13}{*}{ B-lactams } & Penicillins & ampicillin & + & + & + \\
\hline & & amoxicillin/clavulanic acid & + & + & + \\
\hline & & penicillin $\mathrm{V}$ & + & + & + \\
\hline & & oxacillin & + & + & + \\
\hline & & ticarcillin & + & + & + \\
\hline & Cephalosporins & cefalotin $\left(1^{\text {st }}\right)$ & + & + & + \\
\hline & & cefamandole $\left(2^{\text {nd }}\right)$ & + & + & + \\
\hline & & cefoxitin $\left(2^{\text {nd }}\right)$ & + & + & + \\
\hline & & cefepime $\left(2^{\text {nd }}\right)$ & + & - & + \\
\hline & & cefuroxime $\left(2^{\text {nd }}\right)$ & + & - & + \\
\hline & & cefotaxime $\left(3^{\text {rd }}\right)$ & + & - & + \\
\hline & & ceftazidime $\left(3^{\text {rd }}\right)$ & + & + & + \\
\hline & & cefixime $\left(3^{\text {rd }}\right)$ & + & + & + \\
\hline
\end{tabular}

\section{Cephalosporin mediated changes in phenotype}

Bacterial biofilm formation by $S$. aureus is a serious problem especially associated with the pathogenesis of implantable device-related infections, contributing to increased morbidity and mortality [21,22]. It is known that biofilm detachment is controlled by the agr quorumsensing system [23-25] and because we observed opposite modulation of the agr-controlled spa gene when treated with the closely related antibiotics cefalotin and cefotaxime, we chose to investigate their influence on biofilm formation of $S$. aureus 8325-4. At sub-inhibitory concentrations both compounds reduced biofilm formation but the effect was most pronounced in the cefalotin exposed cultures (Figure 2). In our disc diffusion assay we observed increased expression of RNAIII when $S$. aureus was treated with cefalotin and cefotaxime (Table 1). Thus, the reduced biofilm formation correlates with an increased agr activity that previously has been shown to increase the detachment of $S$. aureus from biofilm and reduce biofilm $[18,23,25]$. The effect of subinhibitory cephalosporins on biofilm formation has been studied earlier with contradictory effect; here cefalotin and cephalexin respectively resulted in a denser biofilms $[20,26]$. These discrepancies may be explained by variations in methods used to study biofilm formation. Also, strain 8325-4 carries a mutation in rsbu that diminishes SigB activity [27]. Such strain variation is quite common in $S$. aureus and may explain differences between studies.

\section{Minor structural changes modulate spa differently}

In our screen we had observed a differential modulation of spa expression when exposed to the closely related cephalosporins, cefalotin and cefotaxim. While both substances stimulated RNAIII transcription, cefalotin stimulated and cefotaxim repressed transcription of spa. This result was verified using qRT-PCR (Figure 3). Cefalotin and cefotaxime are $1^{\text {st }}$ and $2^{\text {nd }}$ generation cephalopsporins, respectively. Subrt et al. (2011) suggested that the generations of cephalosporines may cause the differences in spa expression [20]. In accordance with our data, they also found spa to be strongly stimulated by cefalotin $\left(1^{\text {st }}\right.$ generation) but reduced by cefoperazone ( $3^{\text {rd }}$ generation). To address the relationship between chemical structure, generation and spa expression in more detail we included additional cephalosporins with only minor structural differences (results summarized in Table 1 ). We tested cefoxitin and cefamandole, two $2^{\text {nd }}$ generation cefalosporins for their effect on spa regulation and found them to stimulate spa while cefepime, another $2^{\text {nd }}$ generation cephalosporin, down-regulated spa (Figure 1). An additional $3^{\text {rd }}$ generation cephalosporin 


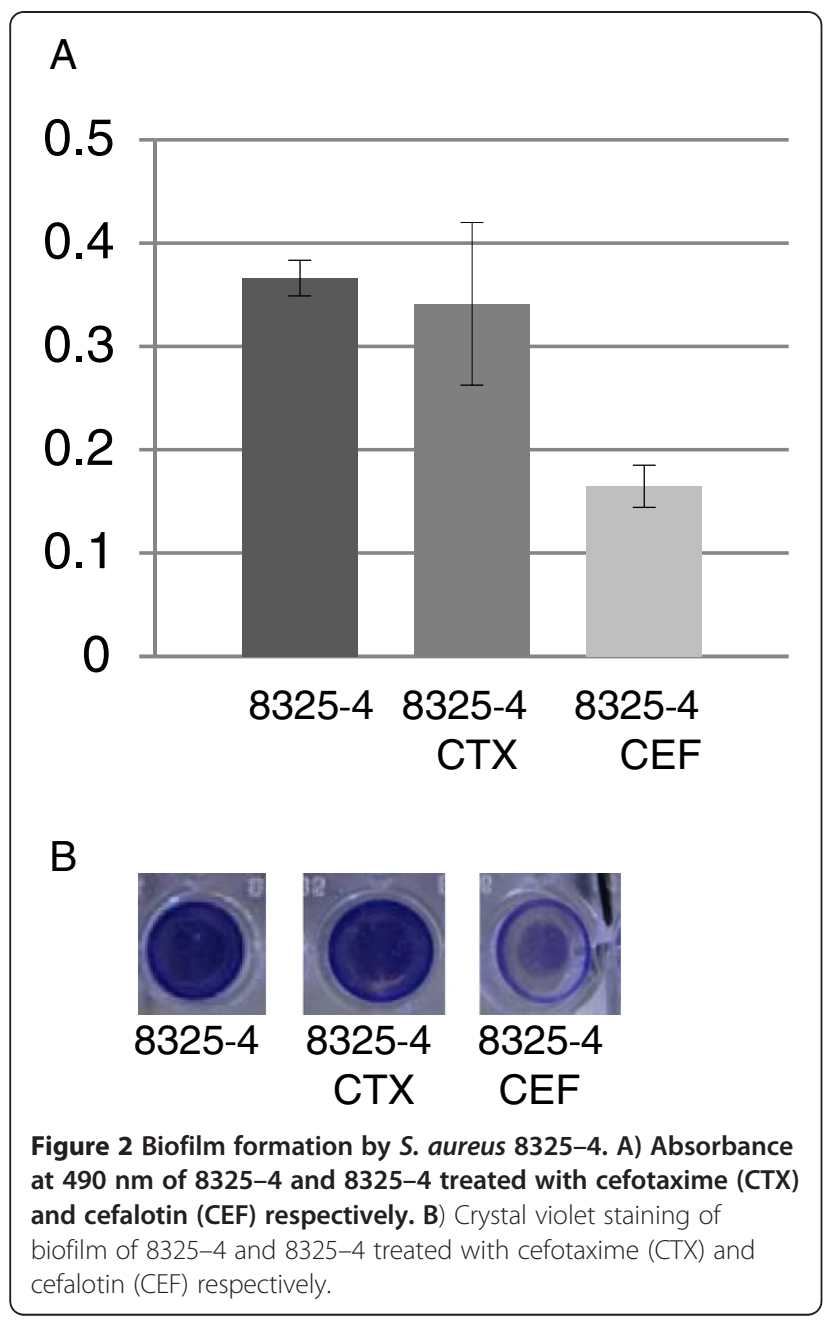

(ceftazidime) stimulated spa. Overall, these results indicate that the variable effects of cephalosporins on spa expression is not linked to the generation of the given cephalosporin but rather to specific structural features of the compounds. Examination of the chemical structures revealed that compounds reducing spa transcription, namely cefepime, cefuroxime and cefotaxime all have a distinct methyloxime group $\mathrm{N}-\mathrm{O}-\mathrm{CH} 3$, while the remaining have an acidic substituted oxime group, i.e. $\mathrm{N}$ $\mathrm{O}-\mathrm{C}(\mathrm{CH} 3) 2 \mathrm{CO} 2 \mathrm{H}$ or $\mathrm{N}-\mathrm{O}-\mathrm{CH} 2-\mathrm{CO} 2 \mathrm{H}$ (Figure 4). These minor chemical changes could result in different binding affinities to a receptor molecule, such as the PBPSs. Cefalotin, cefamandole, cefoxitin and ceftazidime which stimulated spa have the greatest affinity for PBP1, PBP4 and PBP3 respectively $[17,28-30]$ while cefotaxime and cefuroxime that down-regulated spa have highest affinity for PBP2 [29,31]. The observed down-regulation of spa by the latter two substances coincides with a stimulation of RNAIII (Table 1) correlating with agr-dependence, whereas the simultaneous stimulation of RNAIII and spa transcription by cefalotin, cefoxitin and ceftazidime is remarkable and must be considered $a g r$-independent. In this study we have shown that the differences in spa transcription regulation are not due to cephalosporin generation but may be linked to small structural differences between the compounds. However, further studies are needed to elucidate the underlying mechanism.

\section{Conclusions}

Our study shows that in S. aureus, sub-inhibitory concentrations of antibiotics diversely modulate virulence gene expression and that minor structural changes in the chemical structure have dramatic influence on their effect.

\section{Methods}

\section{Strains and growth conditions}

We used different $S$. aureus strains carrying lacZ promotor fusions in RNAIII, hla and spa. Before experiments, strains were incubated on tryptic soy agar (TSA) and grown overnight at $37^{\circ} \mathrm{C}$. For the disc diffusion assay, an additional overnight incubation at $37^{\circ} \mathrm{C}$ in tryptic soy broth (TSB) aerated by shaking was performed. Strains are listed in Table 2.

\section{Antibiotics, MIC- and sub-MIC determination}

Antibiotics used in this study were: aminoglycosides (amikacin, kanamycin, gentamycin, spectinomycin, streptomycin, tobramycin), fluoroquinolones (ciprofloxacin, enfrofloxacin), and $\beta$-lactams (ampicillin, penicillin, oxacillin, amoxicillin/clavulanic acid, ticarcillin, cefalotin, cefepime, cefotaxime, cefuroxime, cefamandole, cefoxitin, ceftazidine, cefixime). Antibiotics were obtained from Sigma and Antimicrobial Susceptibility Testing discs (AST disc) from Oxoid Limited.

The minimal inhibitory concentrations (MIC) values were determined by broth microdilution assay as recommended by CLSI standards [32]. The sub-

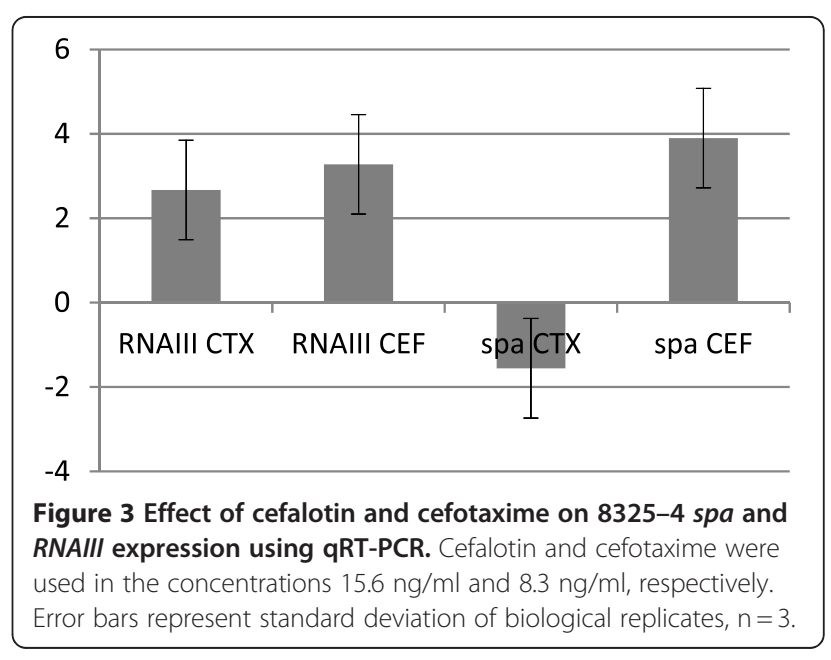




\begin{tabular}{|c|c|c|c|c|}
\hline \multirow{2}{*}{$\begin{array}{l}\text { Cephalosporin } \\
\text { Cefalotin }\end{array}$} & \multirow[t]{2}{*}{ Structure } & \multicolumn{3}{|c|}{$\begin{array}{l}\text { study } \\
\text { sta aureus strains ana constructs usea in this }\end{array}$} \\
\hline & & Strain & Relevant characteristics & Reference \\
\hline & & $8325-4$ & Wild-type strain cured of known prophages & [33] \\
\hline & & JLA341 & SH1000 agr (RNA III):":pAZ106 agr+ & [34] \\
\hline & & PC203 & 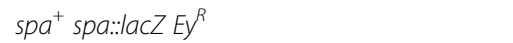 & [35] \\
\hline Cefoxitin & & PC322 & hla $^{+}$hla::lacZ Ey ${ }^{R}$ & [35] \\
\hline
\end{tabular}

applied for every antibiotic. The highest concentration of a given antibiotic that did not visibly inhibit growth was chosen as the individual sub-inhibitory concentration. MIC values for cefalotin and cefotaxime were $10 \mu \mathrm{g} / \mathrm{ml}$ and $0.5 \mu \mathrm{g} / \mathrm{ml}$ respectively while the sub-inhibitory concentrations were $15.6 \mathrm{ng} / \mathrm{ml}$ and $8.3 \mathrm{ng} / \mathrm{ml}$, respectively.

\section{Disc diffusion assay}

Overnight cultures containing the transcriptional lac $Z$ promoter fusions $[34,35]$ were adjusted to $\mathrm{OD}_{600}=$ 0.0035 in $0.9 \% \mathrm{NaCl}$. One $\mathrm{ml}$ of the culture was placed in a petri-dish and mixed with $25 \mathrm{ml}$ of $50^{\circ} \mathrm{C}$ warm TSA supplemented with Erythromycin $(5 \mu \mathrm{g} / \mathrm{ml})$ and X-gal $(150 \mu \mathrm{g} / \mathrm{ml})$. After solidification AST discs were placed on top of the plates and they were incubated for 16 hours at $37^{\circ} \mathrm{C}$. Changes in gene expression were evaluated by visually judging the intensity of the blue color close to the inhibition zone compared to the background.

\section{Quantitative reverse transcriptase PCR}

The effects of sub-inhibitory antibiotic exposure on gene expression was confirmed using quantitative reverse transcriptase PCR (qRT-PCR). Cefalotin and cefotaxime were used in the concentrations $15.6 \mathrm{ng} / \mathrm{ml}$ and $8.3 \mathrm{ng} / \mathrm{ml}$, respectively. $S$. aureus $8325-4$ was grown to $\mathrm{OD}_{600}=1.0$ and RNA purification was done using Qiagen RNeasy mini-prep according to the protocol. The RNA samples were further treated with DNase (Fermentas) before cDNA was made with a RT kit from Applied Biosystems. qRT-PCR was carried out in 96-well microtitre PCR plates (Sarstedt) using the primers listed in Table 3. The housekeeping pyruvate kinase $(p y k)$ was used for normalization.

Table 3 Primers used in this study

\begin{tabular}{lll}
\hline Primer name & Sequence & References \\
\hline rnall-F & GCACTGAGTCCAAGGAAACTAAC & This study \\
rnall- $R$ & AAGCCATCCCAACTTAATAACC & This study \\
spa-F & CAAACGGCACTACTGCTGAC & This study \\
spa-R & CATGGTTGGTGGTTGCTTC & This study \\
pyk-F & AGGTTGAACTCCCCAAACAA & This study \\
pyk-R & GCAGCCCAAGATTACAAAAA & This study \\
\hline
\end{tabular}

$(+)$ up regulation, (-) down regulation of the given promoter::/ac $Z$ fusion.
Figure $\mathbf{4}$ Chemical structures of the Cephalosporins applied in blue circled groups end in a space filling neutral group.

inhibitory concentrations were determined in Erlenmeyer flasks using $\mathrm{OD}_{600}$ to monitor growth of S. aureus 8325-4 [33]. A 2-fold serial dilution starting with the MIC value as the highest concentration was this study. The acidic functional group is circled in red, while the 


\section{Biofilm assay}

Relevant strains were grown to $\mathrm{OD}_{600} 0.2$ at conditions and antibiotic concentrations as described above. Hundred $\mu \mathrm{l}$ pre-culture was added to a 96-well microtiter plate (Sarstedt) and incubated overnight at $37^{\circ} \mathrm{C}$. Then, each well was washed three times with $200 \mu$ physiological saline and stained with $0.1 \%$ crystal violet for $30 \mathrm{~min}$. The crystal violet was washed out and each well washed three times with water. The amount of biofilm was determined by spectrophotometer at $490 \mathrm{~nm}$ after dissolving the crystal violet with $96 \%$ ethanol for $30 \mathrm{~min}$. The test samples were made in triplicate and the experiment repeated three times.

\section{Competing interests}

The authors declare that they have no competing interests.

\section{Authors' contributions}

LN was the primary author of the manuscript, a part of the disc assay screen, qPCR and biofilm assay. MR performed minimum inhibition concentration determination and the majority of disc assay screen. DI participated in analyzing the chemical structures. $\mathrm{HI}$ and $\mathrm{JH}$ designed the study. All authors contributed in writing and reviewing the manuscript. All authors read and approved the final manuscript.

\section{Acknowledgement}

The research was supported by the Danish Council for Independent Research (\# 274-08-0531) and the Lundbeck foundation.

Received: 29 May 2012 Accepted: 19 August 2012

Published: 25 August 2012

\section{References}

1. Davies J: Everything depends on everything else. Clin Microbiol Infect 2009, 15(Suppl 1):1-4. doi:10.1111/j.1469-0691.2008.02682.x. CLM2682 [pii].

2. Kummerer $\mathrm{K}$ : The presence of pharmaceuticals in the environment due to human use-present knowledge and future challenges. J Environ Manage 2009, 90:2354-2366. doi:10.1016/j.jenvman.2009.01.023. 50301-4797 (09)00022-X [pii].

3. Goh EB, Yim G, Tsui W, McClure J, Surette MG, Davies J: Transcriptional modulation of bacterial gene expression by subinhibitory concentrations of antibiotics. Proc Natl Acad Sci U S A 2002, 99:17025-17030. doi:10.1073/ pnas.252607699. 252607699 [pii].

4. Ohlsen K, Ziebuhr W, Koller KP, Hell W, Wichelhaus TA, Hacker J: Effects of subinhibitory concentrations of antibiotics on alpha-toxin (hla) gene expression of methicillin-sensitive and methicillin-resistant

Staphylococcus aureus isolates. Antimicrob Agents Chemother 1998, 42:2817-2823.

5. Walsh C: Molecular mechanisms that confer antibacterial drug resistance. Nature 2000, 406:775-781. doi:10.1038/35021219.

6. Lowy FD: Staphylococcus aureus infections. N Engl J Med 1998, 339:520-532. doi:10.1056/NEJM199808203390806.

7. Otto M: Staphylococcal biofilms. Curr Top Microbiol Immunol 2008, 322:207-228.

8. Bhakdi S, Tranum-Jensen J: Alpha-toxin of Staphylococcus aureus. Microbiol Rev 1991, 55:733-751.

9. Walev I, Martin E, Jonas D, Mohamadzadeh M, Muller-Klieser W, Kunz L, Bhakdi S: Staphylococcal alpha-toxin kills human keratinocytes by permeabilizing the plasma membrane for monovalent ions. Infect Immun 1993, 61:4972-4979.

10. Gomez MI, Lee A, Reddy B, Muir A, Soong G, Pitt A, Cheung A, Prince A: Staphylococcus aureus protein A induces airway epithelial inflammatory responses by activating TNFR1. Nat. Med. 2004, 10:842-848. doi:10.1038/ nm1079. nm1079 [pii].

11. Palmqvist N, Foster T, Tarkowski A, Josefsson E: Protein A is a virulence factor in Staphylococcus aureus arthritis and septic death. Microb Pathog 2002, 33:239-249. S0882401002905334 [pii].
12. Labandeira-Rey M, Couzon F, Boisset S, Brown EL, Bes M, Benito Y, Barbu EM, Vazquez V, Hook M, Etienne J, Vandenesch F, Bowden MG:

Staphylococcus aureus Panton-Valentine leukocidin causes necrotizing pneumonia. Science 2007, 315:1130-1133. doi:10.1126/science.1137165. 1137165 [pii].

13. George EA, Muir TW: Molecular mechanisms of agr quorum sensing in virulent staphylococci. ChemBioChem 2007, 8:847-855. doi:10.1002/ cbic.200700023.

14. Novick RP: Autoinduction and signal transduction in the regulation of staphylococcal virulence. Mol Microbiol 2003, 48:1429-1449. 3526 [pii].

15. Novick RP, Geisinger E: Quorum sensing in staphylococci. Annu Rev Genet 2008, 42:541-564. doi:10.1146/annurev.genet.42.110807.091640.

16. Novick RP, Ross HF, Projan SJ, Kornblum J, Kreiswirth B, Moghazeh S: Synthesis of staphylococcal virulence factors is controlled by a regulatory RNA molecule. EMBO J 1993, 12:3967-3975.

17. Georgopapadakou NH, Smith SA, Bonner DP: Penicillin-binding proteins in a Staphylococcus aureus strain resistant to specific beta-lactam antibiotics. Antimicrob Agents Chemother 1982, 22:172-175.

18. Horswill AR, Nauseef WM: Host interception of bacterial communication signals. Cell Host. Microbe 2008, 4:507-509. doi:10.1016/j.chom.2008.11.003. S1931-3128(08)00370-3 [pii].

19. Kuroda H, Kuroda M, Cui L, Hiramatsu K: Subinhibitory concentrations of beta-lactam induce haemolytic activity in Staphylococcus aureus through the SaeRS two-component system. FEMS Microbiol Lett 2007, 268:98-105. doi:10.1111/j.1574-6968.2006.00568.x. FML568 [pii].

20. Subrt $N$, Mesak $L R$, Davies J: Modulation of virulence gene expression by cell wall active antibiotics in Staphylococcus aureus. $J$ Antimicrob Chemother 2011, 66:979-984. doi:10.1093/jac/dkr043. dkr043 [pii].

21. Bahna P, Dvorak T, Hanna H, Yasko AW, Hachem R, Raad I: Orthopaedic metal devices coated with a novel antiseptic dye for the prevention of bacterial infections. Int J Antimicrob Agents 2007, 29:593-596. doi:10.1016/j.ijantimicag.2006.12.013. S0924-8579(07) 00028-3 [pii].

22. Stefani S, Goglio A: Methicillin-resistant Staphylococcus aureus: related infections and antibiotic resistance. Int J Infect Dis 2010, 14(Suppl 4):S19-S22. doi:10.1016/.jiji.2010.05.009. S1201-9712(10)02367-2 [pii].

23. Boles BR, Horswill AR: Agr-mediated dispersal of Staphylococcus aureus biofilms. PLoS.Pathog 2008, 4:e1000052. 10.1371/journal. ppat.1000052 [doi].

24. Vuong C, Saenz HL, Gotz F, Otto M: Impact of the agr quorum-sensing system on adherence to polystyrene in Staphylococcus aureus. I Infect Dis 2000, 182:1688-1693. doi:10.1086/317606. JID000516 [pii].

25. Yarwood JM, Bartels DJ, Volper EM, Greenberg EP: Quorum sensing in Staphylococcus aureus biofilms. J Bacteriol 2004, 186:1838-1850.

26. Haddadin RN, Saleh S, Al-Adham IS, Buultjens TE, Collier PJ: The effect of subminimal inhibitory concentrations of antibiotics on virulence factors expressed by Staphylococcus aureus biofilms. J Appl Microbiol 2010, 108:1281-1291. doi:10.1111/j.13652672.2009.04529.x. JAM4529 [pii].

27. Giachino P, Engelmann S, Bischoff M: Sigma(B) activity depends on RsbU in Staphylococcus aureus. J Bacterio/ 2001, 183:1843-1852. doi:10.1128/ JB.183.6.1843-1852.2001.

28. Georgopapadakou NH, Liu FY: Binding of beta-lactam antibiotics to penicillin-binding proteins of Staphylococcus aureus and Streptococcus faecalis: relation to antibacterial activity. Antimicrob Agents Chemother 1980, 18:834-836.

29. Neu HC: Relation of Structural Properties of Beta-lactam Antibiotics to Anticacterial Activity. Am J Med 1985, 79. Ref Type: Generic.

30. Stone GW, Zhang Q, Castillo R, Doppalapudi VR, Bueno AR, Lee JY, Li Q, Sergeeva M, Khambatta G, Georgopapadakou NH: Mechanism of action of NB2001 and NB2030, novel antibacterial agents activated by betalactamases. Antimicrob Agents Chemother 2004, 48:477-483.

31. Georgopapadakou NH, Dix BA, Mauriz YR: Possible physiological functions of penicillin-binding proteins in Staphylococcus aureus. Antimicrob Agents Chemother 1986, 29:333-336.

32. Clinical and Laboratory Standards Instutute: Performance Standards for Antimicrobial Susceptibility Testing. M100-S15, CLSI, Wayne, PA, USA: Fifteenth Informational Supplement; 2005. Ref Type: Generic.

33. Novick R: Properties of a cryptic high-frequency transducing phage in Staphylococcus aureus. Virology 1967, 33:155-166. 0042-6822(67) 90105-5 [pii]. 
34. Horsburgh MJ, Aish JL, White IJ, Shaw L, Lithgow JK, Foster SJ: sigmaB modulates virulence determinant expression and stress resistance: characterization of a functional rsbU strain derived from Staphylococcus aureus 8325-4. J Bacteriol 2002, 184:5457-5467.

35. Chan PF, Foster SJ: The role of environmental factors in the regulation of virulence-determinant expression in Staphylococcus aureus 8325-4. Microbiology 1998, 144(Pt 9):2469-2479.

doi:10.1186/1756-0500-5-457

Cite this article as: Nielsen et al: Diverse modulation of spa transcription by cell wall active antibiotics in Staphylococcus aureus. BMC Research Notes 2012 5:457.

\section{Submit your next manuscript to BioMed Central and take full advantage of:}

- Convenient online submission

- Thorough peer review

- No space constraints or color figure charges

- Immediate publication on acceptance

- Inclusion in PubMed, CAS, Scopus and Google Scholar

- Research which is freely available for redistribution 